\title{
STUDY OF FLEET ASSIGNMENT PROBLEM USING A HYBRID TECHNIQUE BASED ON MONTE CARLO SIMULATION AND GENETIC ALGORITHM
}

\author{
E. G. Okafor ${ }^{1,}{ }^{*}$, O. C. Ubadike ${ }^{2}$, N. H. Anene ${ }^{3}$, K. O. Uhuegho ${ }^{4}$ and M. A. Soladoye ${ }^{5}$ \\ 1, 2, FACULTY OF Air ENGineERING, AIR ForCE INSTITUTE OF TECHNOLOGY, NAF BASE KADUNA, NIGERIA \\ 3,4, Aviation Management School, Nigerian College of Aviation TeCH., Zaria, Kaduna State Nigeria \\ 5, LiNKAGE SeRVices, KWARA State University, PMB 1530 MALETE, KWARA STATE, NIGERIA \\ E-mail addresses: ${ }^{1}$ eg.okafor@gmail.com, ${ }^{2}$ diketronics@yahoo.com, ${ }^{3}$ nneka.anene@yahoo.com, \\ ${ }^{4}$ kole_k45@yahoo.com, ${ }^{5}$ musibau.soladoye@kwasu.edu.ng
}

\begin{abstract}
Fleet assignment problem (FAP) is the assignment of an aircraft model to each scheduled flight based on key operational variables such as cost, revenue, passenger travel demand and aircraft specifications. FAP is an important aspect of aircraft planning within an airline. While many developed economy have automated this planning task, developing economy such as Nigeria mainly depend on manpower to carry out this task. The aim of this paper is to solve a FAP using a hybrid technique based on the combination of Monte-Carlo (MC) simulation and Genetic Algorithm (GA). The objective function is total cost and variation in aircraft models and passenger traffic associated with different scheduled flight were considered. MC simulation which was carried out based on the numerical approximation of normal distribution cumulative distribution function (cdf) was used to estimate the expected passenger spill rate, while genetic algorithm was used for the optimization. The result was found to be satisfactory, as optimal fleet plan was achieved in approximately fifteen seconds of program run time, as against not less than an hour usually spend using human effort to solve FAP. Also the optimized plan resulted to a thirty percent saving in comparison to the actual plan implemented by the airline. It is therefore recommended that MC-GA optimization technique should be considered as an alternative technique applicable for FAP optimization.
\end{abstract}

Keywords: Fleet assignment, genetic algorithm Monte-Carlo simulation, optimization

\section{INTRODUCTION}

Fleet Assignment Problem is simply the assignment of an aircraft model to each scheduled flight based on the passenger demand, operating cost and planned revenue of each flight [1]. The outcome of an optimal fleet assignment exercise usually result to the establishment of the plan that minimizes the total operating cost or maximizes revenue as well as addresses linking problems between flight, such as flight gate assignment, aircraft maintenance route and crew assignment. Considering the important of fleet assignment, extensive research work has been carried out in many developing and developed countries located in Asia, Europe and America [2]. However, this trend of extensive FAP studies is presently lacking within countries located in Africa most especially Nigeria. The peculiar lack or limited FAP research scenario in Nigeria has been mainly attributed to smaller number of aircrafts among Nigerian airline operators, low local air travel patronage, which therefore result to limited route coverage. However, with some airline such Air Peace increasing their fleet size as well as opening more routes locally and internationally, the aviation competition on the increase, there is an urgent need for airlines especially in Nigeria to address airline operational, planning and management issues effectively. Generally, research on FAP has been studied in past from diverse perceptive.

* Corresponding author, tel: +234-816-660-5114 
A robust mathematical model for FAP has been studied by Mou and Zhang [1]. Quiet a number of algorithms have been used by researchers globally to address FAP. Some of which includes improved Grover's algorithms, branch-and -price algorithm as well as genetic algorithm etc [2-5]. Li and $\mathrm{Na}$ [6] implemented partheno-genetic algorithm to solve flight string Vehicle Routing Problem (VRP) model using week as the time unit. Although quiet a number of literature and software based tool exist, which can be used for effective fleet planning, in Nigeria FAPs are usually performed with manpower, which therefore indicates a low level of automation. This paper therefore focuses on the use of Nigerian passenger traffic demand at various airports to establish foundation for aircraft planning and scheduling optimization research study within Nigeria. Hence, the aim of this paper is to solve FAP, through the establishment of the minimum total cost associated with using three (3) different aircraft models scheduled to fly thirty (30) flight legs within Nigeria. In this study optimization based on MonteCarlo (MC)- Genetic Algorithm (GA) technique is proposed, to address FAP. In specific terms, MonteCarlo simulation was used to estimate the expected passenger spill rate associated with using each aircraft model to fly each of the 30 scheduled flight, while GA was used to optimize the total cost.

\section{METHODOLOGY}

\subsection{Research Design}

This study employed historical research design. All collected data were analyzed using combination of Monte-Carlo (MC) simulation and Genetic Algorithm based optimization.

\subsection{Data Collection}

The seat capacity, revenue per available seat mile (RASM), cost per available seat mile (CASM) and the recapture rate were collected for three (3) aircraft models mainly B737-300, B737-500 and ERJ145. Furthermore 20 days passenger demand for 30 flight segment for an airline that prefers to remain anonymous as well as the distance between the two airports for each scheduled flight was collected.

\subsection{Data Analysis}

The fleet assignment optimization problem in this study was solved using genetic algorithm (GA). Section 2.3.1 - 2.3.7provides a detailed description of the study problem formulation as well as the GA implementation procedure.

\subsubsection{Problem Formulation}

This study fleet assignment problem was formulated in agreement with the simplified FAP proposed by ref [7] as given in Equation (1).

$$
\begin{gathered}
\min \sum_{i \in y} \sum_{j \in h} c_{i j} x_{i j} \\
\sum_{i \in y} x_{i j}=1 \quad \begin{array}{c}
\text { Subject to } \\
\text { for } j \in h
\end{array}
\end{gathered}
$$

where:

$$
x_{i j}=\left\{\begin{array}{lr}
1 & \text { if flight } j \text { is assigned to fleet } i \\
0 & \text { otherwise }
\end{array}\right.
$$

$c_{i j}$ is the cost associated with assigning fleet type $j$ to flight $i$

The total cost associated with operating an aircraft on any flight segment was computed as given in Equation (2).

$$
c_{i j}=o c_{i j}+s c_{i j}
$$

Where $o c_{i j}$ and $s c_{i j}$ are the operating and spill cost respectively. $o c_{i j}$ and $s c_{i j}$ were computed using Equation (3) and (4) respectively.

$$
\begin{aligned}
& o c_{i j}=C A S M_{j}+d_{i}+n s_{j} \\
& s c_{i j}=e s p_{j}+R A S M_{j}+d_{i}+r r
\end{aligned}
$$

Where $C A S M_{j}$ is the cost per available seat miles for the $j$ fleet type, $R A S M_{j}$ is the revenue per available seat miles for the $j$ fleet type, $n s_{j}$ number of aircraft seat in aircraft model $j, d_{i}$ is the distance between two airports in miles, $e p_{j}$ is the expected passenger spill rate and $r r$ is the recapture rate. The $e^{2} p_{j}$ was computed using Monte-Carlo simulation, which was based on numerical approximation of a normal distribution cumulative distribution function $(c d f)$, in agreement with ref [8]. Accordingly the normal distribution $c d f$ was computed as shown in Equation (5)

$$
z=\varphi^{-1}(p)= \begin{cases}5.556 \times\left(1-\left(\frac{1-p}{p}\right)^{0.1186}\right), & p \geq 0.5 \\ 5.556 \times\left(1-\left(\frac{p}{1-p}\right)^{0.1186}\right), & p<0.5\end{cases}
$$

Where $\mathbf{Z}$ is the normal distribution Z-score value and $\mathrm{p}$ is the probability value which was randomly generated in this work. Implementation of the MC simulation was carried out using an algorithm whose codes were written using MATLAB as presented below:

\section{MC-Simulation Algorithm \\ Set value for $\bar{x}$ and $\sigma$ \\ Set sum $=0$ \\ For $I=1-1000$}

Vol. 38, No. 2, July 2019 


$$
\begin{gathered}
\text { Generate random number } p \\
\text { If } p \geq 0.5 \\
z=\varphi^{-1}(p)=5.556 \times\left(1-\left(\frac{1-p}{p}\right)^{0.1186}\right) \\
\text { Else } \\
z=\varphi^{-1}(p)=5.556 \times\left(1-\left(\frac{p}{1-p}\right)^{0.1186}\right) \\
\text { End } \\
X=z \times \sigma+\bar{x} \\
\text { If } X \leq n s_{j} \\
\text { Else } \quad b=0 \\
\text { End } \quad b=X-n s_{j} \\
\text { Sum }=\text { Sum }+b \\
\text { End } \quad \text { Sum } \\
\text { esp } p_{i}=\frac{1000}{100}
\end{gathered}
$$

where $\bar{x}$ and $\sigma$ represent the mean and standard deviation associated with 20 days passenger demand on each flight segment considered (See appendix I).

\subsubsection{Solution Encoding}

The three (3) aircraft models used are represented by 1, 2, and 3, which correspond to B737-300, B737-500, ERJ145 respectively. The solution was encoded in a chromosome represented by a $(1,30)$ matrix. Thirty (30) used represents the total number of scheduled flight. A possible FAP solution encoding is shown Figure 1. This represents a possible fleet assignment plan for the 30 scheduled flight with B 737-300, B737500 and ERJ145 scheduled for flight legs $(3,6,11,16,23,30), \quad(5,8,14,17,21,28,29) \quad$ and $(1,2,4,9,10,12,13,15,18,19,20,23,24, \quad 25,26,27)$ respectively.

[3 313221123313323123332133333 $221]$

Figure 1: Solution encoding

\subsubsection{Initial Population}

A population size of twenty (20) was used in this study.

\subsubsection{Crossover}

A crossover probability of 0.75 was used in this work as the breeding operator. A random number [0-1] window of same size with the chromosome was generated based on the breeding operator. Genes were exchange between parents at all points in the random number window corresponding to a random numbers greater is equal to the crossover probability (0.75) as shown in Figure 2.

[3 31221123213323123332133333221$]$

[113131211132132121121211212123]

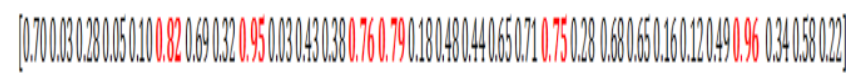

[3312211212131331233221333322 21] [113131213132322121131211213123]

Figure 2: Crossover

\subsubsection{Mutation}

The mutation operator executes random alterations to the generated off-spring using a simple mutation condition. The value within the solution matrix was randomly modified at a randomly generated mutation rate with values less or equal to 0.05. Random mutation operator of same size with the chromosome were generated with a MatLab function rand $(\mathbf{1}, \mathbf{3 0})$. A gene with fleet type (FT) 1 or 2 at all points in which mutation can occur is converted to $F T+1$ respectively. Otherwise are converted to FT-1 (see Figure 3).

\subsubsection{Genetic Algorithm}

The genetic algorithm implemented in this study is given as shown below

Step 1: Start with a randomly generated initial population of size. Set,

Step 2: Assign a fitness value for solution, by performing the following steps:



Figure 3: Mutation 
Step 2.1: Calculate the fitness of the solution as

O Step 2.2: Calculates the selection probability of each solution as follow:

O Step 2.3 Perform crossover and mutation on the selected parents based on their selection probability.

O Step 2.4 Compute the fitness of the two offspring generated using Equation (6).

$$
\rho_{s x}=\left(f(x)-f^{\min }\right) / \sum_{y \in P}\left(f(y)-f^{\min }\right) \text { where } f^{\min }=n
$$

Step 3: Insert the two offspring into an archive of size $P$, then compare the fitness values of the current offspring with that of the existing solution in the archive and eliminate the weakest 2 solutions.

Step 4: If the stopping criterion is satisfied, return chromosome with the minimum total cost. Else go to Step 2.

\subsubsection{Termination Criteria}

In this study the termination criteria is chosen to be 1000. This means that the program will stop after one thousand (1000) iterations.

\section{RESULTS AND DISCUSSION}

The FAP considered in this study was carried out using 2 Boeing and 1 Embraer aircraft models. The choice of these aircraft models was based on the fleet composition of the major domestic carrier in Nigeria (See Appendix II). Table 1 shows key information for the aircraft types considered.

Using Equations (2-4) the total operating cost per segment for the 30 segment considered in this work were obtained for the three (3) aircraft models (see Table 2). All airports were designated in agreement with International Air Transport Association (IATA) airport code as shown in Table 2. Implementation of the genetic algorithm described in section 2.3, the minimum cost required to operate the 30 scheduled flight was found to be approximately $\$ 26,453,060$. This cost was reached after 443 iteration of the algorithm as shown in Figure 4.

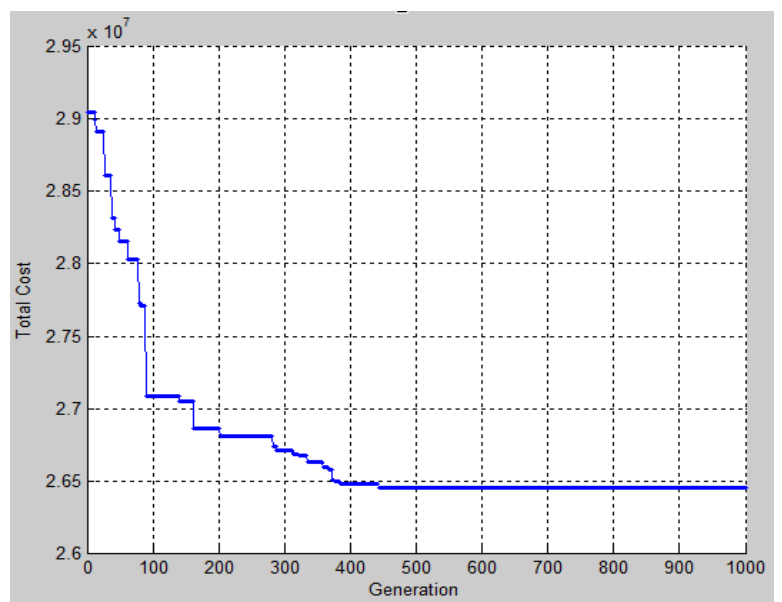

Figure 4: A plot of total cost against GA number of iteration

Subsequently, the fleet assignment plan that brought about the minimum cost of $\$ 26,453,060$ associated with successfully running 30 segment is given in Table 3. The $26,453,060$ optimized cost reached from this study represented approximately $30 \%$ saving when compared to the fleet plan implemented by the airline,

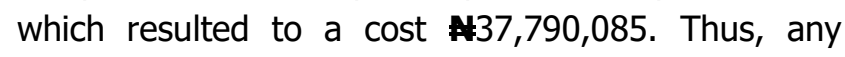
deviation from this fleet assignment shown in table will result to a higher operational cost and should be discouraged. While in this study only three (3) and thirty (30) segments were considered. The written program can be adjusted to reflect any number of aircrafts and flight segment. The total time required to develop a flight plan using the condition set out in this study was 15 seconds, which is considered extremely efficient in terms of time associated with reaching a flight plan in comparison to a minimum time of one (1) hour using human effort to solve the same problem.

Table1: Key information on the three aircraft models used in this study

\begin{tabular}{cccccc}
\hline Aircraft code & Aircraft model type & CASM & RASM & Recapture rate $(r r)$ & Maximum passenger \\
\hline 1 & B 737-300 & 27.1925 & 58.4 & 0.1 & 126 \\
2 & B 737-500 & 29.93 & 51.1 & 0.1 & 110 \\
3 & ERJ 145 & 33.215 & 43.8 & 0.1 & 50 \\
\hline
\end{tabular}


Study of Fleet Assignment Problem using a Hybrid Technique Based on Monte Carlo Simulation and... , E. G. Okafor, et. al

Table 2: Cost associated with using each aircraft model to fly each scheduled flight

\begin{tabular}{ccccc}
\hline S/N & Scheduled flight & B737-300 (Naira) & B737-500 (Naira) & ERJ-145 (Naira) \\
\hline 1 & LOS - ABV & $1.1046 \mathrm{e}+06$ & $1.0978 \mathrm{e}+06$ & $1.2064 \mathrm{e}+06$ \\
2 & ABV - LOS & $1.1023 \mathrm{e}+06$ & $1.0861 \mathrm{e}+06$ & $1.1674 \mathrm{e}+06$ \\
3 & LOS - BNI & $5.2597 \mathrm{e}+05$ & $5.1285 \mathrm{e}+05$ & $4.8394 \mathrm{e}+05$ \\
4 & ENU - LOS & $9.9844 \mathrm{e}+05$ & $9.6985 \mathrm{e}+05$ & $9.8679 \mathrm{e}+05$ \\
5 & KAD - LOS & $1.3495 \mathrm{e}+06$ & $1.3140 \mathrm{e}+06$ & $1.4023 \mathrm{e}+06$ \\
6 & QUO - ABV & $9.5825 \mathrm{e}+05$ & $9.2234 \mathrm{e}+05$ & $7.6399 \mathrm{e}+05$ \\
7 & QOW - LOS & $8.9472 \mathrm{e}+05$ & $8.8590 \mathrm{e}+05$ & $9.1091 \mathrm{e}+05$ \\
8 & ABV - BNI & $7.8098 \mathrm{e}+05$ & $7.5247 \mathrm{e}+05$ & $6.0219 \mathrm{e}+05$ \\
9 & PHC - ABV & $1.0257 \mathrm{e}+06$ & $9.9763 \mathrm{e}+05$ & $8.7177 \mathrm{e}+05$ \\
10 & KAN - ABV & $7.7801 \mathrm{e}+05$ & $7.4784 \mathrm{e}+05$ & $5.6375 \mathrm{e}+05$ \\
11 & LOS - PHC & $9.4387 \mathrm{e}+05$ & $9.2431 \mathrm{e}+05$ & $9.8837 \mathrm{e}+05$ \\
12 & CBQ - ABV & $9.8581 \mathrm{e}+05$ & $9.4736 \mathrm{e}+05$ & $7.1549 \mathrm{e}+05$ \\
13 & ABV - ABB & $6.7430 \mathrm{e}+05$ & $6.7073 \mathrm{e}+05$ & $4.0168 \mathrm{e}+05$ \\
14 & AKR - LOS & $4.6136 \mathrm{e}+05$ & $4.4336 \mathrm{e}+05$ & $3.3047 \mathrm{e}+05$ \\
15 & ABV - ENU & $6.1910 \mathrm{e}+05$ & $5.9546 \mathrm{e}+05$ & $5.4191 \mathrm{e}+05$ \\
16 & YOL - ABV & $1.2130 \mathrm{e}+06$ & $1.1761 \mathrm{e}+06$ & $1.0670 \mathrm{e}+06$ \\
17 & LOS - QUO & $1.1199 \mathrm{e}+06$ & $1.0765 \mathrm{e}+06$ & $9.1814 \mathrm{e}+05$ \\
18 & ABV - QOW & $8.4455 \mathrm{e}+05$ & $8.2172 \mathrm{e}+05$ & $8.6562 \mathrm{e}+05$ \\
19 & LOS - CBQ & $1.2145 \mathrm{e}+06$ & $1.1671 \mathrm{e}+06$ & $7.9073 \mathrm{e}+05$ \\
20 & QOU - LOS & $1.1199 \mathrm{e}+06$ & $1.0762 \mathrm{e}+06$ & $7.4063 \mathrm{e}+05$ \\
21 & QOW - YOL & $1.5568 \mathrm{e}+06$ & $1.4961 \mathrm{e}+06$ & $9.4476 \mathrm{e}+05$ \\
22 & ABV - YOL & $1.2106 \mathrm{e}+06$ & $1.1634 \mathrm{e}+06$ & $8.9671 \mathrm{e}+05$ \\
23 & LOS - ABB & $7.8865 \mathrm{e}+05$ & $7.5798 \mathrm{e}+05$ & $5.1706 \mathrm{e}+05$ \\
24 & CBQ - LOS & $1.2145 \mathrm{e}+06$ & $1.1671 \mathrm{e}+06$ & $8.8613 \mathrm{e}+05$ \\
25 & ABV - PHC & $1.0219 \mathrm{e}+06$ & $9.8878 \mathrm{e}+05$ & $9.4339 \mathrm{e}+05$ \\
26 & KAN - LOS & $1.7921 \mathrm{e}+06$ & $1.8232 \mathrm{e}+06$ & $2.0912 \mathrm{e}+06$ \\
27 & QOW - ABV & $8.4446 \mathrm{e}+05$ & $8.1898 \mathrm{e}+05$ & $8.0991 \mathrm{e}+05$ \\
28 & LOS - ENU & $1.0026 \mathrm{e}+06$ & $9.8673 \mathrm{e}+05$ & $1.0119 \mathrm{e}+06$ \\
29 & LOS - KAD & $1.3486 \mathrm{e}+06$ & $1.2981 \mathrm{e}+06$ & $1.2605 \mathrm{e}+06$ \\
30 & YOL - LOS & $2.2283 \mathrm{e}+06$ & $2.1414 \mathrm{e}+06$ & $1.5244 \mathrm{e}+06$ \\
\hline & & & &
\end{tabular}

Table 3: Optimized fleet assignment plan

\begin{tabular}{ccc}
\hline S/N & Scheduled Flight & Assigned Aircraft \\
\hline 1 & LOS- ABV & B737-500 \\
2 & ABV - LOS & B737-500 \\
3 & LOS - BNI & ERJ145 \\
4 & ENU - LOS & B737-500 \\
5 & KAD - LOS & B737-500 \\
6 & QUO - ABV & ERJ145 \\
7 & QOW - LOS & B737-500 \\
8 & ABV - BNI & ERJ145 \\
9 & PHC - ABV & ERJ145 \\
10 & KAN - ABV & ERJ145 \\
11 & LOS - PHC & B737-500 \\
12 & CBQ - ABV & ERJ145 \\
13 & ABV - ABB & ERJ145 \\
14 & AKR - LOS & ERJ145 \\
15 & ABV - ENU & ERJ145
\end{tabular}




\begin{tabular}{ccc}
\hline S/N & Scheduled Flight & Assigned Aircraft \\
\hline 16 & YOL - ABV & ERJ145 \\
17 & LOS - QUO & ERJ145 \\
18 & ABV - QOW & B737-500 \\
19 & LOS - CBQ & ERJ145 \\
20 & QOU - LOS & ERJ145 \\
21 & QOW - YOL & ERJ145 \\
22 & ABV - YOL & ERJ145 \\
23 & LOS - ABB & ERJ145 \\
24 & CBQ - LOS & ERJ145 \\
25 & ABV - PHC & ERJ145 \\
26 & KAN - LOS & B737-300 \\
27 & QOW - ABV & ERJ145 \\
28 & LOS - ENU & B737-500 \\
29 & LOS - KAD & ERJ145 \\
30 & YOL - LOS & ERJ145 \\
\hline
\end{tabular}

\section{CONCLUSIONS AND RECOMMENDATION}

In this study fleet assignment problem was considered using three (3) aircrafts models and 30 scheduled flight within Nigerian. Monte-carlo simulation was used to predict the expected passenger spill rate for each aircraft model used in the study, which was subsequently used to compute the total cost, while genetic algorithm was used to optimize the total cost required to operate the three (3) aircraft models for the 30 scheduled flights considered. From the result it was concluded that the sum $\mathrm{A26,453,060}$ is required to successfully use B737-300, B737-500 and ERJ145 to operate the 30 scheduled flights based on the optimized flight plan reached in this study. Also the optimized plan resulted to a thirty percent saving in comparison to the actual plan implemented by the airline. It is therefore recommended that MC-GA optimization technique should be considered as an alternative technique applicable for FAP optimization.

\section{ACKNOWLEDGEMENTS}

This work was supported by the Nigerian College of Aviation Technology (NCAT) Zaria Special Research Fund (SRF) 2018.

\section{REFERENCES}

[1] Mou, D. and Zhang Z. "Robust fleet scheduling problem based on probability of flight delay, "Journal of Civil Aviation University of China, Vol. 28, Issue 6, 2010, pp.35-39.

[2] Zhang, W., Kamgarpour M., Sun, D. "A hierarchical flight planning framework for air traffic management," Proceedings of the IEEE, Vol. 100, Issue1, 2012, pp.179-194.

[3] Sherali, H. D., Bish, E. K. and Zhu, X. "Airline fleet assignment concepts, models and algorithms," European Journal of Operational Research, Vol. 172, Issue1, 2006, pp.1-30.

[4] Li, Y. and $\mathrm{Na}, \mathrm{T} .$, "Study on fleet assignment problem model and algorithm," Mathematical Problems in Engineering, Article ID 581586, 2013, pp.1-5.

[5] Nabil, K., Aida, J., Ali, D., "An integrated flight scheduling and fleet assignment problem under uncertainty," Computer \& Operation Research Vol. 100, 2018, pp.333-342.

[6] Li, Y. and $\mathrm{Na}, \mathrm{T}$. , "Study on flight-string optimization based on partheno-genetic algorithm," Proceeding of the $8^{\text {th }}$ World Congress on Intelligent Control and automation (WCICA '10) Jinan, China. 2010, pp. 4093-4096.

[7]' 'Hane, C. A., Barnhart, C., Johnson, E. L. Marsten R. E. Nemhauser G. L., and Sigismondi G., "The fleet assignment problem: Solving a large-scale integer program," Mathematical Programming. Vol. 70, 1995, pp. 211-232.

[8] John, S. "The three parameter two piece normal family of distributions and its fitting," Communications in Statistics- Theory and Methods. Vol. 11, Issue 8, 1982, pp.879-885.

Vol. 38, No. 2, July 2019 


\section{APPENDIX I: TWENTY DAYS PASSENGER DEMAND FOR THE STUDY THIRTY SCHEDULED FLIGHTS}

\begin{tabular}{|c|c|c|c|c|c|c|c|c|c|c|c|c|c|c|c|c|c|c|c|c|c|c|c|c|}
\hline $\mathrm{S} / \mathrm{N}$ & Segment & $d_{i}$ (Miles) & 1 & 2 & 3 & 4 & 5 & 6 & 7 & 8 & 9 & 10 & 11 & 12 & 13 & 14 & 15 & 16 & 17 & 18 & 19 & 20 & $\overline{\bar{x}}$ & $\sigma$ \\
\hline 1 & LOS-ABV & 278.7 & 120 & 100 & 87 & 115 & 90 & 105 & 85 & 110 & 80 & 90 & 122 & 125 & 105 & 98 & 110 & 125 & 126 & 88 & 97 & 100 & 103 & 14.4 \\
\hline 2 & $A B V-L O S$ & 278.7 & 125 & 95 & 105 & 75 & 86 & 110 & 99 & 89 & 105 & 120 & 110 & 97 & 79 & 86 & 126 & 105 & 110 & 96 & 103 & 84 & 100 & 14.1 \\
\hline 3 & LOS-BNI & 133 & 57 & 73 & 62 & 110 & 97 & 86 & 110 & 105 & 77 & 96 & 120 & 69 & 84 & 106 & 59 & 92 & 83 & 104 & 120 & 68 & 88 & 19.6 \\
\hline 4 & ENU - LOS & 253 & 75 & 100 & 97 & 120 & 83 & 79 & 101 & 99 & 87 & 73 & 105 & 116 & 93 & 81 & 107 & 88 & 96 & 74 & 98 & 115 & 94 & 13.8 \\
\hline 5 & KAD - LOS & 342 & 120 & 80 & 100 & 92 & 97 & 86 & 96 & 105 & 94 & 115 & 81 & 90 & 118 & 120 & 99 & 102 & 87 & 96 & 106 & 91 & 98 & 11.9 \\
\hline 6 & QUO-ABV & 243 & 57 & 64 & 59 & 73 & 84 & 100 & 92 & 79 & 64 & 86 & 54 & 100 & 63 & 82 & 99 & 78 & 59 & 100 & 96 & 69 & 77 & 15.8 \\
\hline 7 & QOW-LOS & 225 & 64 & 79 & 126 & 121 & 97 & 84 & 105 & 69 & 110 & 94 & 78 & 86 & 120 & 115 & 120 & 125 & 74 & 99 & 87 & 102 & 97 & 19.2 \\
\hline 8 & $A B V-B N I$ & 198 & 46 & 63 & 57 & 100 & 82 & 93 & 72 & 59 & 48 & 100 & 99 & 63 & 91 & 77 & 86 & 90 & 94 & 64 & 48 & 55 & 74 & 18.5 \\
\hline 9 & PHC - ABV & 259 & 120 & 105 & 79 & 96 & 105 & 49 & 61 & 73 & 56 & 49 & 110 & 105 & 96 & 81 & 70 & 47 & 59 & 82 & 66 & 115 & 81 & 23.3 \\
\hline 10 & KAN-ABV & 197.3 & 53 & 82 & 90 & 72 & 66 & 89 & 48 & 71 & 88 & 90 & 42 & 61 & 81 & 74 & 67 & 54 & 47 & 90 & 84 & 70 & 70 & 15.5 \\
\hline 11 & LOS - PHC & 239 & 120 & 97 & 105 & 81 & 92 & 113 & 84 & 96 & 117 & 86 & 94 & 101 & 120 & 112 & 87 & 92 & 82 & 105 & 91 & 120 & 99 & 13.1 \\
\hline 12 & CBQ- ABV & 250 & 80 & 75 & 61 & 73 & 66 & 62 & 77 & 68 & 72 & 80 & 77 & 64 & 72 & 63 & 79 & 63 & 69 & 74 & 80 & 71 & 71 & 6.4 \\
\hline 13 & $A B V-A B B$ & 177 & 65 & 70 & 41 & 56 & 36 & 63 & 57 & 70 & 39 & 45 & 68 & 54 & 69 & 38 & 70 & 38 & 70 & 54 & 62 & 42 & 55 & 12.5 \\
\hline 14 & AKR - LOS & 117 & 73 & 54 & 82 & 68 & 85 & 71 & 62 & 59 & 79 & 83 & 62 & 70 & 59 & 63 & 85 & 73 & 57 & 71 & 64 & 85 & 70 & 9.9 \\
\hline 15 & ABV-ENU & 157 & 93 & 100 & 73 & 82 & 100 & 64 & 87 & 75 & 92 & 99 & 80 & 64 & 79 & 92 & 71 & 86 & 92 & 100 & 71 & 96 & 84 & 11.9 \\
\hline 16 & YOL-ABV & 307 & 62 & 84 & 59 & 71 & 97 & 101 & 88 & 120 & 112 & 87 & 92 & 54 & 63 & 82 & 98 & 71 & 118 & 97 & 72 & 63 & 84 & 19.4 \\
\hline 17 & LOS - QUO & 284 & 96 & 72 & 100 & 87 & 64 & 92 & 63 & 79 & 81 & 90 & 72 & 85 & 74 & 63 & 60 & 72 & 78 & 92 & 84 & 93 & 79 & 11.8 \\
\hline 18 & $A B V-Q O W$ & 214 & 81 & 96 & 87 & 110 & 105 & 86 & 93 & 120 & 82 & 107 & 98 & 80 & 96 & 113 & 87 & 92 & 116 & 86 & 94 & 117 & 97 & 12.5 \\
\hline 19 & LOS $-C B Q$ & 308 & 56 & 62 & 40 & 72 & 69 & 80 & 79 & 58 & 64 & 71 & 75 & 65 & 48 & 63 & 52 & 74 & 43 & 67 & 80 & 77 & 64 & 11.8 \\
\hline 20 & QOU - LOS & 284 & 80 & 53 & 74 & 50 & 64 & 72 & 67 & 73 & 55 & 69 & 80 & 52 & 70 & 62 & 59 & 73 & 50 & 62 & 79 & 72 & 65 & 9.8 \\
\hline 21 & QOW-YOL & 394.8 & 53 & 47 & 54 & 74 & 35 & 60 & 80 & 52 & 49 & 79 & 55 & 73 & 61 & 49 & 62 & 59 & 37 & 54 & 72 & 66 & 59 & 12.4 \\
\hline 22 & $A B V-Y O L$ & 307 & 64 & 77 & 50 & 85 & 59 & 90 & 72 & 87 & 57 & 82 & 78 & 84 & 71 & 63 & 59 & 78 & 53 & 69 & 89 & 73 & 72 & 12.1 \\
\hline 23 & LOS - ABB & 200 & 81 & 90 & 76 & 42 & 57 & 82 & 71 & 35 & 48 & 61 & 57 & 69 & 83 & 71 & 51 & 87 & 39 & 48 & 63 & 57 & 63 & 16.2 \\
\hline 24 & $\mathrm{CBQ}-\mathrm{LOS}$ & 308 & 63 & 50 & 71 & 66 & 84 & 90 & 77 & 63 & 83 & 57 & 72 & 87 & 64 & 57 & 72 & 83 & 58 & 74 & 88 & 74 & 71 & 11.5 \\
\hline 25 & $A B V-P H C$ & 259 & 105 & 83 & 72 & 98 & 60 & 88 & 104 & 120 & 93 & 112 & 69 & 89 & 75 & 69 & 86 & 92 & 110 & 93 & 79 & 87 & 88 & 15.6 \\
\hline 26 & KAN-LOS & 451 & 108 & 110 & 97 & 121 & 113 & 120 & 102 & 126 & 99 & 126 & 124 & 111 & 92 & 108 & 125 & 123 & 100 & 117 & 93 & 90 & 110 & 12 \\
\hline 27 & QOW-ABV & 214 & 96 & 102 & 86 & 77 & 110 & 97 & 72 & 86 & 70 & 113 & 120 & 92 & 88 & 79 & 86 & 74 & 74 & 93 & 121 & 89 & 91 & 15.1 \\
\hline 28 & LOS-ENU & 253 & 102 & 98 & 87 & 110 & 78 & 70 & 86 & 122 & 124 & 114 & 96 & 82 & 70 & 97 & 117 & 78 & 88 & 79 & 98 & 124 & 96 & 17.3 \\
\hline 29 & LOS - KAD & 342 & 92 & 85 & 70 & 92 & 100 & 97 & 72 & 83 & 110 & 92 & 107 & 78 & 100 & 92 & 86 & 92 & 73 & 81 & 102 & 91 & 89 & 11.1 \\
\hline 30 & YOL - LOS & 565.1 & 73 & 64 & 80 & 57 & 40 & 63 & 74 & 80 & 76 & 63 & 59 & 69 & 49 & 68 & 72 & 89 & 80 & 53 & 65 & 72 & 67 & 11.6 \\
\hline
\end{tabular}

\section{Appendix II: Nigerian Airline Operators Fleet Size}

\begin{tabular}{|c|c|c|c|c|c|c|c|c|c|c|c|c|c|c|c|c|c|c|c|c|c|c|c|c|c|c|}
\hline \multirow{2}{*}{ 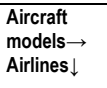 } & \multirow{2}{*}{$\begin{array}{l}\text { Airbus } \\
\text { A319- } \\
100 \\
\end{array}$} & \multicolumn{2}{|c|}{ ATR } & \multirow{2}{*}{$\begin{array}{l}\text { Beechcraft } \\
1900 \mathrm{D} \\
\end{array}$} & \multicolumn{10}{|c|}{ Boeing } & \multicolumn{3}{|c|}{ Bombardier } & \multirow{2}{*}{\begin{tabular}{|l} 
Dornier \\
$328-300$ \\
\end{tabular}} & \multicolumn{2}{|c|}{ Embraer } & \multicolumn{2}{|c|}{$\begin{array}{c}\text { McDonnell } \\
\text { Douglass }\end{array}$} & \multicolumn{3}{|c|}{ De Havilland } & \multirow[t]{2}{*}{ Total } \\
\hline & & $\begin{array}{l}\text { ATR } \\
42\end{array}$ & $\begin{array}{l}\text { ATR } \\
72\end{array}$ & & $\begin{array}{l}737- \\
300\end{array}$ & $\begin{array}{l}737- \\
400\end{array}$ & $\begin{array}{l}737- \\
500\end{array}$ & $\begin{array}{l}737- \\
700\end{array}$ & $\begin{array}{l}737 . \\
800\end{array}$ & $\begin{array}{l}737 . \\
\text { Max }\end{array}$ & $\begin{array}{l}747 . \\
400\end{array}$ & $\begin{array}{l}767 . \\
\text { 300ER }\end{array}$ & $\begin{array}{l}777- \\
\text { 200ER }\end{array}$ & $\begin{array}{l}777-5 \\
300\end{array}$ & $\begin{array}{l}\text { CRJ } \\
900\end{array}$ & \begin{tabular}{|l} 
CRJ \\
1000 \\
\end{tabular} & $\begin{array}{l}Q Q \\
400\end{array}$ & & $\begin{array}{l}\text { ERJ } \\
145 \\
\end{array}$ & $\begin{array}{l}\text { Legacy } \\
600\end{array}$ & MD 82 & $\begin{array}{l}\text { MD } \\
83\end{array}$ & $\begin{array}{l}\text { Dash 8- } \\
\text { Q200 }\end{array}$ & $\begin{array}{l}\text { Dash 8- } \\
\text { Q300 }\end{array}$ & $\begin{array}{l}\text { Dash 8- } \\
\text { Q400 }\end{array}$ & \\
\hline $\begin{array}{l}\text { Aero } \\
\text { Contractor }\end{array}$ & & & & & & 1 & 2 & & & & & & & & & & & & & & & & 1 & 1 & 2 & 7 \\
\hline Arik & & & & & & & & 9 & 4 & & & & & & 4 & 1 & 4 & & & & & & & & & 22 \\
\hline Air Peace & & & & & 8 &  & 5 & & & & & & 1 & 1 & & & & 1 & 6 & & & & & & & 22 \\
\hline Azman Air & & & & & 2 & 2 & & & & & & & & & & & & & & & & & & & & 4 \\
\hline DANA Air & & & & & & & & & & & & & & & & & & & & & 1 & 3 & & & & 4 \\
\hline First nation & 2 & & & & & & & & & & & & & & & & & & & & & & & & & 2 \\
\hline Medview & & & & & & & 2 & 1 & & & & 1 & 1 & & & & & & & & & & & & & 5 \\
\hline Overland & & 4 & 3 & 2 & & & & & & & & & & & & & & & & & & & & & & 9 \\
\hline Max Air & & & & & 3 & 4 & & & & & & & & & & & & & & 1 & & & & & & 8 \\
\hline
\end{tabular}

